\title{
Peningkatan Perekonomian Masyarakat dengan Pemberdayaan Bahan Baku Kulit Singkong Di Desa Padamulya Kabupaten Cianjur Melalui Pelatihan Pembuatan Pakan Alternatif
}

\section{Improving Community Economy With Empowerment of Singkong Skin Raw Materials In Padamulya Village, Cianjur District Through Training of Alternative Feeding}

\author{
Lingga Kelana Ramadhan ${ }^{1}$ \\ ${ }^{1}$ Program Studi Ekonomi Syariah, Fakultas Ekonomi Islam, Universitas Djuanda Bogor Jl. Tol Ciawi No. 1, \\ Kotak Pos 35 Ciawi, Bogor 16720, e-mail: lingga.kelana.ramadhan@unida.ac.id
}

(Diterima: 25-06-2020; Ditelaah: 15-12-2020; Disetujui: 10-06-2021)

\begin{abstract}
Abstrak
Di Kampung Padamulya Desa Padamulya belum ada inovasi produk olahan kulit singkong biasanya kulit singkong tidak dimanfaatkan atau hanya dibuang saja padahal desa ini memiliki potensi singkong yang besar. Oleh karena itu, dibutuhkannya sosialisasi kepada masyarakat tentang inovasi produk dan cara pengolahan singkong menjadi pakan ternak alternatif. Tujuan kegiatan ini adalah untuk meningkatkan penghasilan masyarakat Desa Padamulya Kecamatan Pasirkuda Kabupaten Cianjur. Metode yang digunakan adalah sosialisasi dan praktek mengolah diversifikasi produk berbahan dasar kulit singkong yaitu pelatihan pembuatan pakan ternak alternatif. Adapun metode pembuatan kulit singkong adalah dengan mencucinya dengan air mengalir sampai bersih lalu jemur sampai kering kemudian potong dan tiriskan kecil-kecil lalu rendam dan kukus selama 30 menit diamkan selama 1 hari kemudian produk siap diberikan ke ternak. Hasil yang diperoleh adalah menambah wawasan dan informasi tentang pembuatan pakan ternak alternatif. Setelah pengabdian ini dilakukan, masyarakat mulai menyadari pentingnya pengolahan hasil pertanian yaitu singkong untuk meningkatkan penghasilan dan memasarkan produknya secara online.
\end{abstract}

Kata kunci: Pelatihan, Pembuatan Produk Kulit Singkong, Pakan Ternak Alternatif

\begin{abstract}
In Padamulya Village, Padamulya Village, there has not yet been an innovation in processed cassava skin products. Usually, cassava skin is not used or just thrown away, even though this village has a large cassava potential. Therefore, we need socialization to the public about product innovation and how to process cassava into Alternative Animal Feed. The purpose of this activity is to increase the income of the people of Padamulya Village, Pasirkuda District, Cianjur Regency. The method used is the socialization and practice of processing the diversification of products made from cassava peel, namely the training in making Alternative Animal Feed. The method of making cassava peel is to wash it with running water until it is clean then dry it to the keri then cut and drain into small pieces then soak and steam for 30 minutes let stand for 1 day then the product is ready to be given to cattle. The results obtained are adding insight and information about making Alternative Animal Feed. After this service was made, the community began to realize the importance of processing agricultural products, namely cassava to increase income and market their products online.
\end{abstract}

Keywords: Training, Making Cassava Coolies Products, Alternative Animal Feed

\section{PENDAHULUAN}

Singkong merupakan tanaman yang paling banyak di budidayakan di Desa Padamulya Kecamatan Pasirkuda Kabupaten Cianjur. Terlihat dari hasil singkong yang melimpah yaitu $15 \mathrm{Ton} / \mathrm{Ha}$ atau $15 \mathrm{Kg} / \mathrm{M}^{2}$ dari lahan singkong seluas $5 \mathrm{Ha}$. Selain itu mayoritas masyarakat tersebut merupakan produsen dari gula aren. Biasanya kulit singkong hanya dibuang dan tidak dimanfaatkan banyak yang perternak tidak mengetahui kulit singkong 
bisa dijadikan pakan ternak alternatif. Pemanfaatan kulit singkong untuk dijadikan sebuah inovasi produk merupakan suatu harapan masyarakat Desa Padamulya. Sebab Desa tersebut belum memiliki produk yang khas untuk di jual demi bertambahnya pendapatan dan kesejahteraan masyarakat Desa Padamulya. Oleh karena itu, dibutuhkan sosialisasi kepada masyarakat tentang bagaimanacara mengolah kulit singkong Pakan Alternatif.

Pakan Alternatif merupakan inovasi produk olahan pakan dari singkong yang di permentasikan dengan cara di jemur lalu di kukus lalu campurkan bahan-bahan yang diperlukan sehingga ternak bisa memakan pakan tersebut dan tidak berbahaya bagi ternak. Hasil pengabdian yang hanya berupa pengulangan (replikasi) dari hasil pengabdian yang telah dipublikasikan, misal hanya kondisi geografisnya yang berbeda, tidak akan dipertimbangkan untuk dipublikasikan. naskah bernomor seri tidak dapat diterima, kecuali disampaikan dan disajikan pada waktu yang bersamaan.

Diharapkan kegiatan ini mampu menambah bahan pakan dan pendapatan masyarakat desa. Selain itu, produk yang dihasilkan dapat menjadi produk khas Desa Padamulya. Kegiatan pengabdian kepada masyarakat dengan pendekatan pengembangan potensi lokal seperti pengembangan produk Pakan Ternak Alternatif di Desa Padamulya, dapat lebih meningkatkan minat masyarakat untuk terus menggali potensi dalam pemanfaatan sumber daya untuk meningkatkan pendapatan dan kesejahteraan lebih mandiri.

\section{METODE PELAKSANAAN}

Metode pelaksanaan pengabdian kepada masyarakat, yaitu menggunakan metode penyuluhan dan workshop (pelatihan). Pada pelaksanaan program tersebut, ada beberapa tahap yaitu survey lokasi dan potensi lingkungan sekitar Desa Padamulya, sosialisasi produk, pelatihan produksi, pengemasan produk dan pemasaran produk.

1) Survey Lokasi

Survey lokasi dilakukan langsung ke wilayah Kampung Padamulya Desa Padamulya oleh mahasiswa, hasil yang didapatkan dari survey tersebut bahwa di daerah Kampung Padamulya ini terdapat banyak singkong yang dihasilkan dari kebun. Singkong di Kampung Padamulya Desa Padamulya ini biasanya hanya dijual langsung mentahannya saja atau diolah menjadi keripik singkong. Belum ada inovasi produk olahan lain dari singkong.

2) Sosialisasi mengenai inovasi produk

Sebelum diadakannya pelatihan pembuatan produk Bola Manis Si Engkong, penulis melakukan koordinasi kepada perternak setempat mengenai inovasi produk Pakan Ternak dan memberitahu bahwa akan ada pelatihan pembuatan produk Pakan Ternak Alternatif.

3) Pelatihan Produksi

Produksi produk merupakan tahap ketiga setelah sosialisasi produk. Inovasi 
produk tersebut dipraktikkan dengan memproduksi olahan pangan hasil dari inovasi yang akan dipasarkan.

4) Pengemasan Produk

Tahap pengemasan dilakukan pemilihan kemasan platik bening yang sesuai dengan produk dan membuat desain stiker agar lebih menarik.

5) Pemasaran Produk

Pemasaran produk ini dilakukan dengan pembuatan akun Shopee yang telah di buat Kelompok 4. Pemasarannya dilakukan melalui online agar dapat menjangkau pemasaran yang lebih jauh.

Capaian dari kegiatan pemasaran produk Pakan Ternak Alternatif adalah pertama, keberhasilan masyarakat dalam melakan pembuatan produk Pakan Ternak, dan kedua adalah peningkatan pengetahuan masyarakat terhadap tehnik pemasaran, dan terakhir adalah tingginya partisipatif masyarakat dalam kegiatan ini. Dua kegiatan pengabdian masyarakat yang dilakukan di Desa Padamulya yaitu kegiatan produksi yang disertai dengan inovasi melalui pelatihan dan pendampingan dan kegiatan kegiatan pemasaran dengan pemberian pengetahuan dan praktek langsung. Diharapkan tidak hanya menjadi pengetahuan bagi masyarakat tapi dapat dilanjutkan pada tahapan menjadi sumber pendapatan baru di desa Padamulya.

Antusiasme ini ditunjukkan oleh beberapa hal antara lain: kegiatan produksi Pakan Ternak Alternatif ditindaklanjuti dengan kegiatan pemasaran produk. Dalam kegiatan pemasaran produk Bola Manis Si Engkong merupakan bagian dari pendampingan bagi masyarakat terkait dengan proses dari keseluruhan kegiatan. Kegiatan ini diikuti oleh lebih dari 19 ibu-ibu dari DKM Nurul Iman yang derada di Desa Padamulya. Dalam kegiatan ini masyarakat dibimbing untuk melakukan pemasaran langsung dengan memanfaatkan potensi Desa Padamulya.

\section{HASIL \& PEMBAHASAN}

Masyarakat Kampung Padamulya Desa Padamulya memberikan respon baik terhadap pelaksanaan kegiatan pelatihan pembuatan Pakan Ternak Alternatif sehingga kegiatan ini berjalan dengan lancar. Jumlah masyarakat yang hadir dalam kegiatan pelatihan ini sehingga dengan adanya partisipasi masyarakat tersebut menjadikan program ini terlaksana sesuai dengan perencanaan awal.

Setelah praktik pembuatan Pakan Ternak Alternatif, hasil dari pelatihan pemasaran online ini adalah masyarakat terutama yang berusia muda tertarik untuk menjual produk secara online salah satunya di Shopee. Adapun toko yang terbentuk dari hasil pelatihan pemasaran online ini yaitu toko dapur KKN di Shopee yang sudah penulis sesuaikan logo, alamat toko, dan produk yang dijual. 
Ramadhan

Peningkatan Perekonomian Masyarakat dengan Pemberdayaan Bahan Baku Kulit Singkong di Desa Padamulya Kabupaten Cianjur melalui Pelatihan Pembuatan Pakan Alternatif

\section{KESIMPULAN}

Berdasarkan hasil kegiatan PKM yang telah dilaksanakan di Desa Padamulya, Kecamatan Pasirkuda, Kabupaten Cianjur, masyarakat menyadari dan memahami bahwa kulit singkong dapat diolah menjadi Pakan Ternak Alternatif Kegiatan pengolahan Kulit singkong menjadi Pakan Alternatif ini diharapkan mampu menggerakkan perekonomian dan meningkatkan kesejahteraan masyarakat desa.

\section{DAFTAR PUSTAKA}

Maesaroh, S. Kurnia, T (2018). Program Peningkatan Pendapatan Masyarakat Desa Melalui Pemanfaatan Limbah Kulit Pisang Menjadi Produk Kulit Pisang Aneka Rasa (Vol 5 No 2 Edisi Oktober 2018 p-ISSN 2442-3726 e-ISSN 2550-1143) Page 125. 